\title{
Cisplatin Nephrotoxicity and Protection by Milk Thistle Extract in Rats
}

\section{Gholamreza Karimi, Mohammad Ramezani and Zahra Tahoonian}

\author{
Department of Pharmacodynamy and Toxicology, School of Pharmacy, Mashhad University of Medical Sciences, \\ Mashhad, Iran
}

The protective effect of methanolic extract of milk thistle seeds and silymarin against cisplatin-induced renal toxicity in male rats after a single intraperitoneal injection of $3 \mathrm{mg} \mathrm{kg}^{-1}$ cisplatin were studied. Over 5 days, cisplatin-treated rats showed tubular necrosis and elevation in blood urea nitrogen (BUN) and serum creatinine (Scr). Pretreatment of animals with silymarin $\left(50 \mathrm{mg} \mathrm{kg}^{-1}\right)$ or extract $\left(0.6 \mathrm{~g} \mathrm{~kg}^{-1}\right) 2 \mathrm{~h}$ before cisplatin prevented the tubular damage. Rats treated with silymarin or extract $2 \mathrm{~h}$ after cisplatin had BUN and Scr significantly lower than those receiving cisplatin, but mild to moderate necrosis was observed. These results suggested that milk thistle may protect against cisplatininduced renal toxicity and might serve as a novel combination agent with cisplatin to limit renal injury.

Keywords: cisplatin - milk thistle - renal toxicity - silymarin

\section{Introduction}

Cisplatin is a potent anticancer agent against solid tumors of the testes, ovaries, breasts, lungs, bladder, etc. However, in practice, the use of cisplatin is limited by its marked renal toxicity (1-4). It has been suggested that the generation of reactive oxygen species and lipid peroxidation is responsible for the cisplatin-induced renal tubular injury (5-7).

Flavonoids are naturally occurring substances that possess various pharmacological actions and therapeutic applications. Some due to their phenolic structures have antioxidant effect and inhibit free radical-mediated processes (8-11). Silymarin, a mixture of three isomeric flavonolignans, is isolated from milk thistle (Silybum marianum) seeds. Silymarin is used clinically to treat chronic inflammatory liver disease and hepatic cirrhosis. Hepatoprotection can be attributed to its antioxidant properties by scavenging free radicals and increasing intracellular concentration of glutathione $(12,13)$.

The aim of this study was to evaluate the protective effect of milk thistle methanolic extract and silymarin against cisplatininduced acute renal failure in rats.

For reprints and all correspondence: Dr Gholamreza Karimi, Department of Pharmacodynamy and Toxicology, School of Pharmacy, Mashhad University of Medical Sciences, Mashhad, Khorasan 91775-1365, Iran.

Tel: 0511-8823255; Fax: 0511-8823251; E-mail: gho_karimi@yahoo.com

\section{Materials and Methods}

\section{Animals}

The study was performed on male wistar rats, $8-10$ weeks, 200-240 g that were bred and kept at the animal center of Mashhad School of Pharmacy. They were housed in ventilated rooms at temperature of $24 \pm 2{ }^{\circ} \mathrm{C}$ with a $12 \mathrm{~h} \mathrm{light/dark} \mathrm{cycle}$ and $60 \pm 5 \%$ humidity. They were provided with food and water ad libitum.

\section{Plant Material}

The seeds of milk thistle plant were purchased from local market of Mashhad and authenticated by matching with the specimen available in pharmacognosy section of pharmacy school. A voucher specimen (S/A/102) was also deposited in the school.

\section{Preparation of Extract}

The dried seeds of milk thistle were powdered and $5 \mathrm{~g}$ of the powder was extracted with $95 \%$ methanol $(100 \mathrm{ml})$ thrice, overnight at $28^{\circ} \mathrm{C}$ with continuous stirring. The pooled extracts were evaporated under reduced pressure to a known volume. The residual solvent was evaporated to dryness at $40^{\circ} \mathrm{C}$ on a water bath.

(C) The Author (2005). Published by Oxford University Press. All rights reserved.

The online version of this article has been published under an open access model. Users are entitled to use, reproduce, disseminate, or display the open access version of this article for non-commercial purposes provided that: the original authorship is properly and fully attributed; the Journal and Oxford University Press are attributed as the original place of publication with the correct citation details given; if an article is subsequently reproduced or disseminated not in its entirety but only in part or as a derivative work this must be clearly indicated. For commercial re-use, please contact journals.permissions@oupjournals.org 

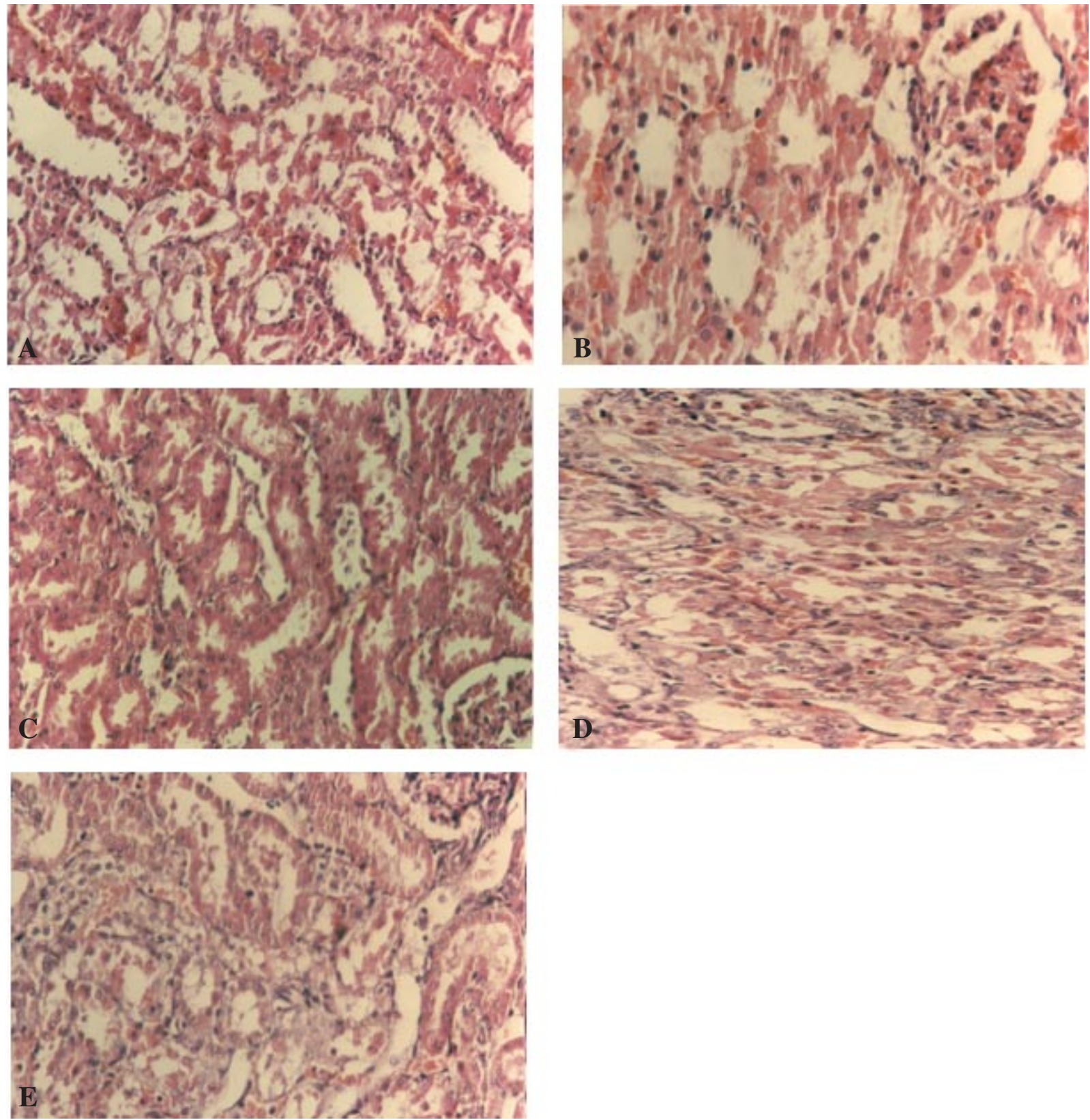

Figure 1. Histological examination. (A) Areas of sever necrosis of proximal tubules, 5 days after injection of $3 \mathrm{mg} \mathrm{kg}^{-1}$ cisplatin. (B) Minimal tubular necrosis after treatment with extract $\left(0.6 \mathrm{~g} \mathrm{~kg}^{-1}\right) 2 \mathrm{~h}$ before cisplatin. (C) Minimal tubular necrosis after treatment with silymarin $\left(50 \mathrm{mg} \mathrm{kg}{ }^{-1}\right) 2 \mathrm{~h} \mathrm{before} \mathrm{cisplatin.}$ (D) Minimal to moderate tubular necrosis after treatment with extract $\left(0.6 \mathrm{~g} \mathrm{~kg}^{-1}\right) 2 \mathrm{~h}$ after cisplatin. (E) Minimal to moderate tubular necrosis after treatment with silymarin $\left(50 \mathrm{mg} \mathrm{kg}^{-1}\right) 2 \mathrm{~h}$ after cisplatin.

\section{Experimental Procedure}

The method is based on the modification of Baliga et al. (14). Four groups of rats $(n=5)$ were used to study the effect of silymarin and methanolic extract on cisplatin-induced renal toxicity and changes in renal function. Group 1 animals received cisplatin $\left(3 \mathrm{mg} \mathrm{kg}^{-1}\right)$ intraperitoneally. Groups 2 and 3 received intraperitoneal methanolic extract $\left(0.6 \mathrm{~g} \mathrm{~kg}^{-1}\right)$ or silymarin (50 $\mathrm{mg} \mathrm{kg}^{-1}$; Sigma, UK) $2 \mathrm{~h}$ before cisplatin injection. Groups 4 and 5 received the same dose of extract or silymarin $2 \mathrm{~h}$ after cisplatin administration. Group 6 acted as vehicle (normal saline $+1 \% \mathrm{w} / \mathrm{v}$ methylcellulose) control. Rats were sacrificed 5 days after cisplatin administration. The protocols used conformed with guidelines of the conduct of animal experiments issued by pharmacy school and were approved by the committee on the ethics of animal experiments in Mashhad University. Blood samples were collected and analyzed for blood urea nitrogen (BUN) and serum creatinine (Scr) by using the commercial kits (15). After bleeding, the kidneys were removed and fixed in $10 \%$ neutral buffered formalin for at least $24 \mathrm{~h}$. Tissues were processed for microscopical examination using a standard protocol and paraffin 
sections were stained with hematoxylin and eosin (16). The changes seen were limited to the tubulointerstitial areas and graded as follows: grade 0 , normal; grade I, areas of tubular epithelial cell swelling, necrosis and desquamation involving $<25 \%$ of cortical tubules; grade II, similar changes involving $>25 \%$ but $<50 \%$ of cortical tubules; grade III, similar changes involving $<50 \%$ but $<75 \%$ of cortical tubules; and grade IV, similar changes involving $>75 \%$ of cortical tubules.

\section{Statistical Analysis}

The results are expressed as mean \pm SEM. Data were analyzed by one-way analysis of variance. Sequential difference among mean were calculated at the level of $P<0.05$, using Tukey contrast analysis as needed.

\section{Results and Discussion}

The injection of cisplatin produced proximal and distal tubular necrosis, mainly in the corticomedullary region and intratubular casts in the outer stripe of the outer medulla (Fig. 1A; grade IV). Functional nephrotoxicity indices such as BUN and Scr were elevated in cisplatin-treated rats compared with saline. Treatment with silymarin or extract $2 \mathrm{~h}$ before cisplatin prevented the increases in BUN and Scr as well as tubular damage (Fig. 1B and C; grades 0 and I). Rats treated with silymarin or extract $2 \mathrm{~h}$ after cisplatin had BUN and Scr levels significantly lower than those receiving cisplatin alone, but mild to moderate cell injury was observed (Fig. 1D and E; grades II and III). The results of renal functional determinations are summarized in Table 1. Our results are in agreement with previous study that showed silibinin $\left(200 \mathrm{mg} \mathrm{kg}^{-1}\right.$, intravenously), one of the component of silymarin, $1 \mathrm{~h}$ before the cisplatin (5 mg kg${ }^{-1}$, intraperitoneally) prevented the effects of cisplatin on creatinine clearance and proteinuria, and diminished morphological alteration in proximal tubules (17).

Induction of nephrotoxicity by cisplatin is assumed to be a rapid process involving reaction with proteins in the renal tubules $(18,19)$. Because this renal damage occurs within $1 \mathrm{~h}$ after administration (20), it is important that the protective agent is present in renal tissue before damage occurs. This

Table 1. Protective effect of silymarin $\left(50 \mathrm{mg} \mathrm{kg}^{-1}\right)$ and methanolic extract of milk thistle $\left(0.6 \mathrm{~g} \mathrm{~kg}^{-1}\right)$ against cisplatin $\left(3 \mathrm{mg} \mathrm{kg}^{-1}\right)$ induced elevation of BUN and Scr

\begin{tabular}{lll}
\hline & $\mathrm{BUN}\left(\mathrm{mg} \mathrm{dl}^{-1}\right)$ & $\mathrm{Scr}\left(\mathrm{mg} \mathrm{dl}^{-1}\right)$ \\
\hline Vehicle & $17.48 \pm 1.80^{* * *}$ & $0.75 \pm 0.05^{* *}$ \\
Cisplatin & $56.80 \pm 2.40$ & $1.50 \pm 0.20$ \\
$\quad$ + Silymarin (2 h before cisplatin) & $31.20 \pm 2.60^{* *}$ & $1.15 \pm 0.05^{*}$ \\
+ Silymarin (2 h after cisplatin) & $30.10 \pm 1.50^{* *}$ & $1.12 \pm 0.09^{*}$ \\
+ Extract (2 h before cisplatin) & $28.00 \pm 2.80^{* *}$ & $1.12 \pm 0.15^{*}$ \\
+ Extract (2 h after cisplatin) & $32.26 \pm 1.70^{* *}$ & $1.05 \pm 0.10^{*}$ \\
\hline
\end{tabular}

$n=5$, mean $\pm \mathrm{SEM} ; * P<0.5, * * P<0.01, * * * P<0.001$ significantly different compared with cisplatin-treated group. might explain why complete protection did not result when silymarin or extract were given after administration of cisplatin. The acute renal failure indicated by increased Scr and BUN occurred before the development of tubular necrosis. These parameters are markers of glomerular filtration rate. However, it cannot be excluded that the enhancement of these parameters may be the result of tubular obstruction or tubular backleak (21). Our finding has been interpreted as a support of the hypothesis that tubular obstruction and/or tubular fluid backleak are not involved in the initiation of acute renal failure in this model of nephrotoxicity.

The mechanisms by which silymarin and extract ameliorate cisplatin toxicity remains to be elucidated. We supposed they may inhibit lipid peroxidation by scavenging free radicals and increasing intracellular concentration of glutathione. Previous studies have indicated that superoxide anions inactivate nitric oxide (NO) and that NO-dependent vascular relaxation is enhanced by superoxide dismutase $(22,23)$. There is a possibility that they could have maintained RBF as a result of preserved NO through scavenging of the superoxide anions. Further studies are needed to determine the exact mechanism of silymarin and extract.

In conclusion, the present finding suggest that $S$. marianum protects against acute cisplatin nephrotoxicity and may be considered as a potentially useful candidate in the combination chemotherapy with cisplatin.

\section{Acknowledgments}

We thank Dr Omidi and Dr Kalantari for helping in histological studies and Vice Chancellor of research for financial support.

\section{References}

1. Rozeneweing M, Van Hoff D, Slavil M, Maggia FM. cis-Diaminedichloroplatinum, a new anticancer agent. Ann Int Med 1977;86:803-9.

2. Winston JA, Safirstein R. Reduced renal flow in early cisplatin-induced acute renal failure in the rat. Am Physiol 1985;249:F490-6.

3. Greggi Antunes LM, Darin JD, Bianchi M. Protective effects of vitamin C against cisplatin-induced nephrotoxicity and lipid peroxidation in adult rats. Pharmacol Res 2000;41:405-11.

4. Chirino YI, Hernandez-pando R, Pedraza-Chaveri J. Peroxynitrite decomposition catalyst ameliorates renal damage and protein nitration in cisplatin-induced nephrotoxicity in rats. BMC Pharmacol 2004;4:20-9.

5. Sugihara K, Nakano S, Koda M, Tanaka K, Fukuishi N, Gemba M. Stimulatory effect of cisplatin on production of lipid peroxidation in renal tissues. Jpn J Pharmacol 1987;43:247-52.

6. Mora L, Antunes LM, Francescato HD, Bianchi M. The effects of oral glutamine on cisplatin-induced nephrotoxicity in rats. Pharmacol Res 2003; 47:517-22.

7. Xiao T, Choudhary S, Zhang W, Ansari NH, Salahudeen A. Possible involvement of oxidative stress in cisplatin-induced apoptosis in LLC-PK1 cells. J Toxicol Environ Health 2003;66:469-79.

8. Havsteen B. Flavonoids, a class of natural products of high pharmacological potency. Biochem Pharmacol 1983;32:1141-8.

9. Mora A, Paya M, Rios J, Alcaraz M. Structure activity relationships of polymetoxyflavones and other flavonoids as inhibitors of non-enzymatic lipid peroxidation. Biochem Pharmacol 1990;40:793-4.

10. Singh D, Chander V, Chopra K. Protective effect of catechin on ischemiareperfusion-induced renal injury in rats. Pharmacol Rep 2005;57:70-6.

11. Zhao B. Natural antioxidants for neurodegenerative diseases. Mol Neurobiol 2005;31:283-94. 
12. DerMarderosian A. The Review of Natural Product. St Louis: Fact and Comparison, 2001, 405-9.

13. Fleming T. PDR for Herbal Medicines. New Jersy: Medical Economics Company, 2000, 516-8.

14. Baliga R, Zhang Z, Baliga M, Ueda N, Shah SV. In vitro and in vivo evidence suggesting a role for iron in cisplatin-induced nephrotoxicity. Kidney Int 1998;53:394-401.

15. McClatchey KD. Clinical Laboratory Medicine. London: Williams \& Wilkins, 1994, 376-8.

16. Hammersen F. Histology. Munich: Urban and Schwarzenberg, $1985,1-4$

17. Gaedeke J, Fels LM, Bokemeyer C, Mengs U, Stolte H, Lentzen H. Cisplatin nephrotoxicity and protection by silibinin. Nephrol Dial Transplant 1996;11:55-62.

18. Heidman HT, Gerkens JF, Jackson EK, Branch RA. Attenuation of cisplatin induced nephrotoxicity in the rat by high salt diet, furosemide and acetazolamide. Arch Pharmacol 1985;329:201-5.
19. Montine TJ, Borch RF. Role of endogenous sulfur containing nucleophiles in an in vitro model of cis-diamminedichloroplatinium-induced nephrotoxicity. Biochem Pharmacol 1990;39:1751-7.

20. Rao M, Rao MM. Protective effects of selenomethionine against cisplatininduced renal toxicity in mice and rats. J Pharm Pharmacol 1992;50: 687-91.

21. Jones TW, Chopra S, Kaufman JS, Flamenbaum W, Trump B. Cisdiammine-dichloroplatinium-induced acute renal failure in the rat. $L a b$ Invest 1985;52:363-74.

22. Rubanyi GM, Vanhoutte PM. Superoxide anions and hypoxia inactivate endothelium derived relaxing factor. Am J Physiol 1986;250: H822-7.

23. Modlinger PS, Wilcox CS, Aslam S. Nitric oxide, oxidative stress, and progression of chronic renal failure. Semin Nephrol 2004;24: 354-65.

Received April 3, 2005; accepted July 3, 2005 


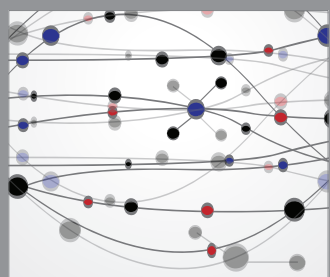

The Scientific World Journal
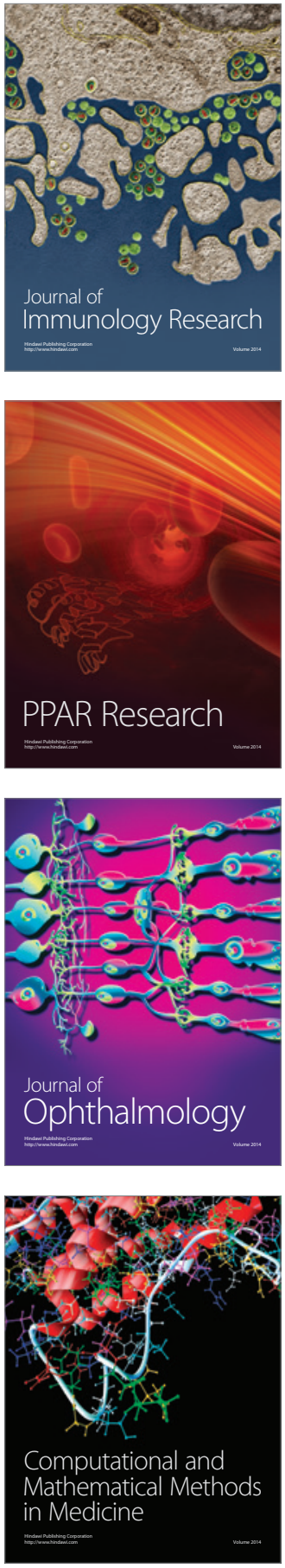

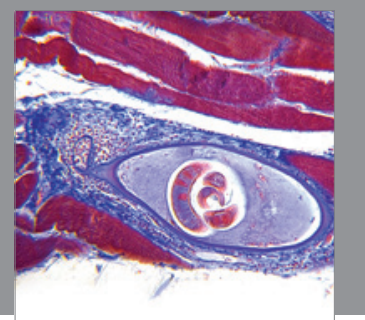

Gastroenterology

Research and Practice
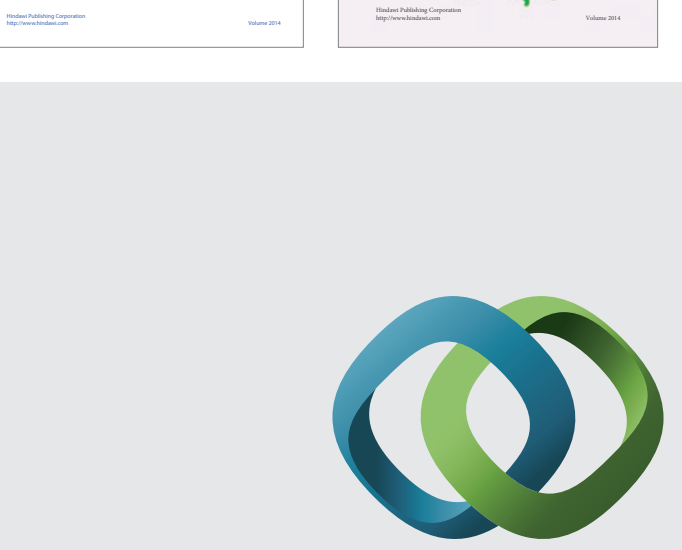

\section{Hindawi}

Submit your manuscripts at

http://www.hindawi.com
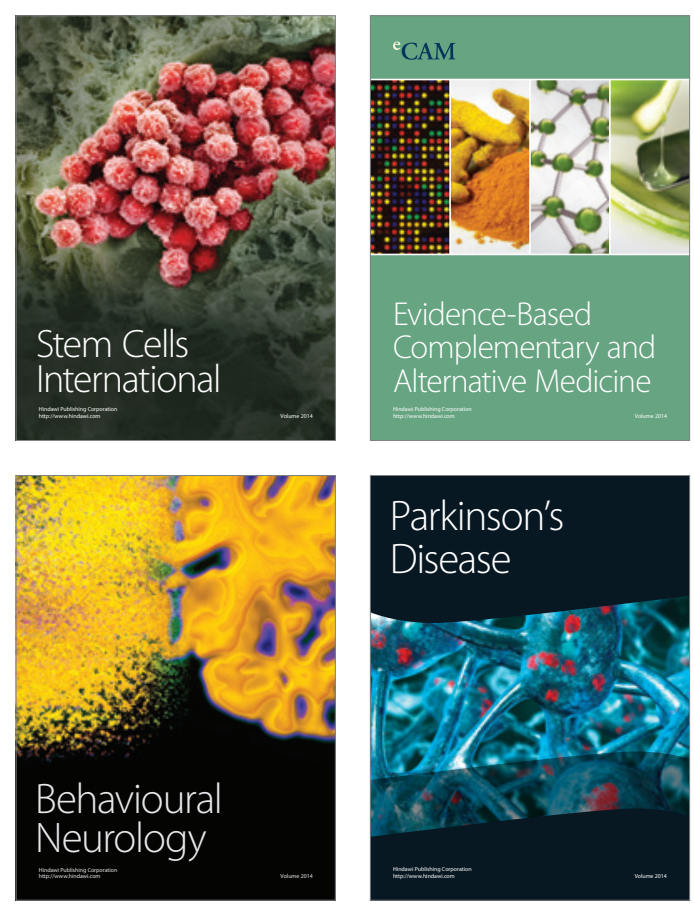

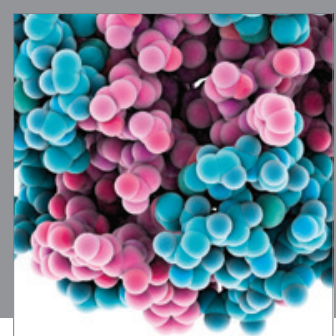

Journal of
Diabetes Research

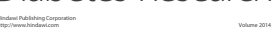

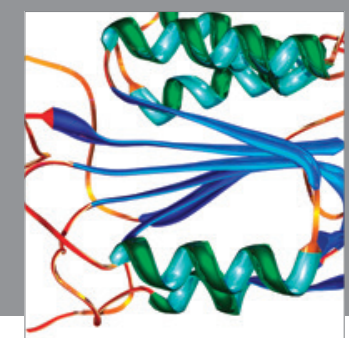

Disease Markers
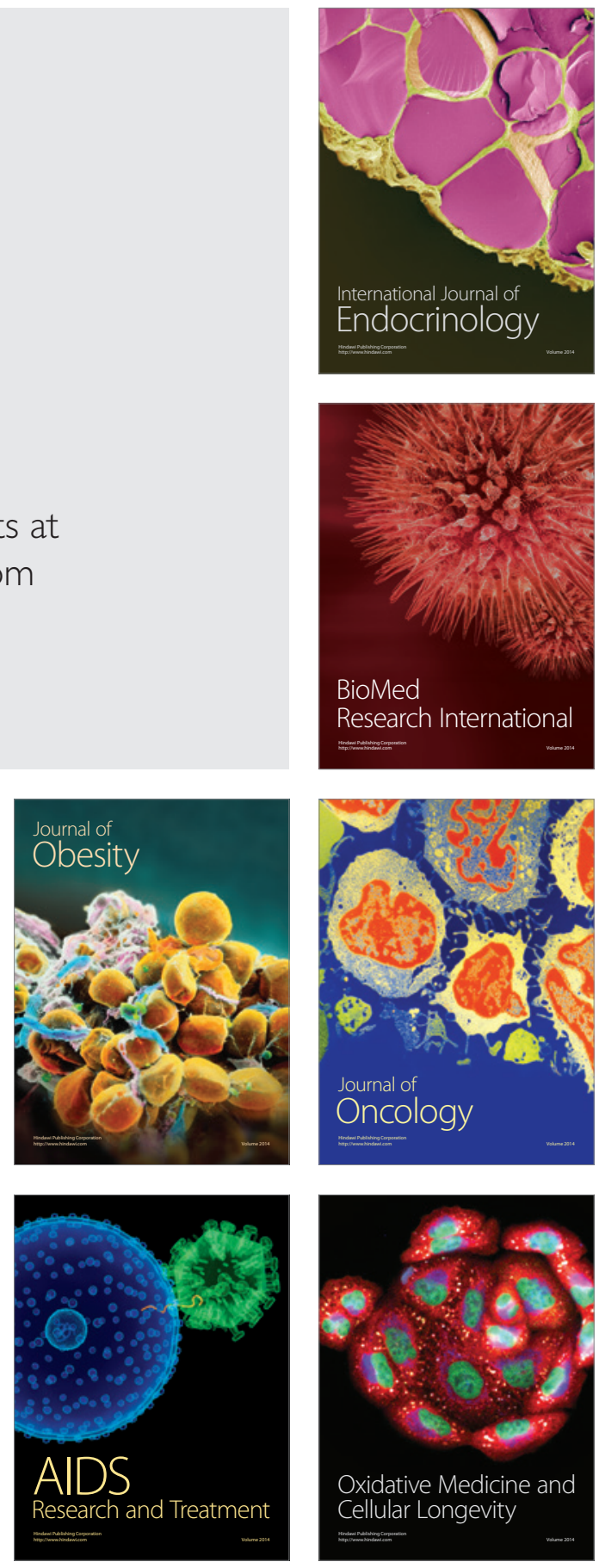